\title{
ESTONIAN STUDENTS' PERCEPTION AND DEFINITION OF CYBERBULLYING
}

\author{
Karin Naruskov ${ }^{1}$, Piret Luik ${ }^{1}$, Annalaura Nocentini ${ }^{2}$, and Ersilia Menesini ${ }^{2}$ \\ ${ }^{1}$ University of Tartu and ${ }^{2}$ University of Florence
}

\begin{abstract}
Rapid development of information and communication technologies is having a direct impact on the lives of adolescents, and a new form of bullying has emerged. This study aims to examine how Estonian students perceive and define cyberbullying based on five cyberbullying criteria (imbalance of power, intention, repetition, anonymity, and publicity/privacy) and four types of cyberbullying behaviour (written-verbal, visual, exclusion, and impersonation). A quali-quanti approach was used consisting of focus groups and a questionnaire. Two mixed-gender focus groups of 12- and 15-year-old students were interviewed to deepen their perception in relation to cyberbullying criteria and behaviours. Results were used for the quantitative study. The questionnaire was conducted with 336 adolescents from twelve Estonian schools, aged from 11 to 17 years. Results by MDS revealed a two-dimensional model characterized by imbalance of power and anonymity. This study can help to improve understanding of the phenomenon with respect to student perceptions.
\end{abstract}

Keywords: cyberbullying, definition, scenarios, criteria of cyberbullying, types of cyberbullying, Estonia

DOI: $10.3176 /$ tr.2012.4.02

\section{Introduction}

The issue of a construct definition is a relevant problem in different research areas, especially when dealing with new areas of research such as cyberbullying. In this area an increasing number of recent studies have focused on the issues of defining and measuring cyberbullying (Gradinger et al. 2010, Grigg 2010, Menesini and Nocentini 2009, Vandebosch and Cleemput 2008). In many cases the cyberbullying definition has been based on Olweus' original bullying definition (Hinduja and Patchin 2009, Smith et al. 2008). According to Dan Olweus (1999:10) we can say: "a student is being bullied or victimized when he or she is exposed, repeatedly and over time, to negative actions on the part of one or more 
other students". This definition emphasizes three criteria that are important in order to define bullying behaviour: intentionality, repetition, and imbalance of power (Olweus 1999). Although the general definition of bullying is still relevant, its expressions have changed dramatically over several years (Smith et al. 2002) to include the recent form of cyberbullying or bullying in the virtual domain. Following the Olweus definition, Smith et al. (2008:376) have defined cyberbullying as: "an aggressive, intentional act carried out by a group or individual, using electronic forms of contact, repeatedly, and over time against a victim who cannot easily defend him or herself". This definition refers directly to the definition of traditional bullying; the only difference is that technological devices are used for carrying out the attacks. From this scientific definition it seems that cyberbullying is just one expression of traditional bullying. However, some recent contributors have expressed doubts around the traditional bullying criteria suggested by Olweus (1999): these are not always easily distinguishable, recognizable, and sometimes even sufficient in the cyber world context (Hinduja and Patchin 2009, Kowalski and Limber 2007, Menesini and Nocentini 2009, Shariff 2008, Slonje and Smith 2008). In addition, it is assumed that there are new cyber-specific criteria that are particular to communication with new technologies (i.e. publicity vs. privacy and anonymity vs. known person) (Menesini and Nocentini 2009, Nocentini et al. 2010, Slonje and Smith 2008). Taken together, these considerations highlight how cyberbullying should be considered partially as a new phenomenon and researchers need to investigate it more thoroughly ( $\mathrm{Li} 2007)$.

Apart from different scholars' definitions we must also consider possible differences between researchers, children, and adolescents. Several studies on traditional bullying highlight how, for young participants, the definition is not always consistent with the scientific one (Menesini et al. 2002, Smith et al. 2002, Vaillancourt et al. 2008). One of the differences seems to relate to terms used to denote the problem in different languages, another relates to different perspectives of the problem (children vs. adolescents, adults vs. young participants) (Smith et al. 2002, Smorti et al. 2003).

According to Vandebosch and Cleemput (2008) it is necessary to develop a clear definition of cyberbullying that is consistent with students' perceptions because the lack of conceptual clarity may lead us to a situation where researchers and respondents perceive the phenomenon differently. Several qualitative studies have already focused on the issue of students' perceptions of cyberbullying underlying the role of some traditional criteria but also the specificities of this problem (Grigg 2010, Mishna et al. 2009, Vandebosch and Cleemput 2008).

The primary focus of this paper is to investigate students' perception and definition of cyberbullying. More precisely, our aim is to know which term Estonian students use to define the problem and to analyse which criteria are relevant for the Estonian students' definition of cyberbullying. 


\subsection{Five criteria of cyberbullying \\ 1.1.1. Intentionality}

Olweus (1999) recognized that the degree of perpetrator awareness of how the bullying is perceived by victims varies greatly. Nevertheless, Olweus (1999) believes that the majority of the perpetrators intend to harm the victim. In the cyber context the intentionality is more difficult to identify due to the nature of communication in this context (Kowalski et al. 2008, Menesini and Nocentini 2009). In face-to-face interactions our behaviours are influenced by the emotional reactions of others, but in a virtual environment communication is mainly indirect and it is difficult to understand a person's emotions or really understand the consequences of one person's behaviour. Therefore, the perpetrator's intentions and victim's reaction may remain partly hidden for both bullies and victims (Kowalski et al. 2008). Nocentini et al. (2010) conducted focus group interviews among adolescents in three different European countries: Italy, Germany, and Spain. In relation to intentionality, participants agree that intentionality is important but it cannot be viewed independently from the imbalance of power because the effect on the victim and his/her perception of the acts can also be more relevant than the intentions behind the aggressor's behaviour in order to establish the seriousness and the nature of the behaviour.

\subsubsection{Imbalance of power}

Olweus' (1999) definition emphasizes the actual or perceived imbalance of power in bullying behaviour; it follows that bullying is not a situation when there is a conflict between two persons of equal physical and mental characteristics. In addition to the actual or perceived weakness, power imbalance can be achieved through gossiping, social exclusion, and anonymous bullying when the perpetrator(s) is difficult to identify or confront (Olweus 1999). According to Grigg (2010), in the context of cyberbullying, the imbalance of power lies in situations where the target "cannot easily defend him or herself" because of the aggressive act of the perpetrator(s). Even so, the results of Nocentini et al. (2010) indicated that the imbalance of power and the intent to harm have to be viewed in relation to one another; the students agreed that if the victim is affected by the behaviour then the behaviour must be considered cyberbullying. In virtual environment the imbalance of power may have been caused by 'real life' power criteria involving for example physical strength or age or by the perpetrator's greater computer proficiency (Dooley et al. 2009, Hinduja and Patchin 2008, Kowalski et al. 2008, Vandebosch and Cleemput 2008). Grigg (2010) argues that imbalance of power may also build on the situational advantage(s) that the bully has over the victim, such as a high social status in some online group together with the support of other members of the group. Furthermore, the anonymous and public nature of the attack and the continuous availability of the victim may create an imbalance in power relations (Dooley et al. 2009, Kowalski et al. 2008, Slonje and Smith 2008). 


\subsubsection{Repetition}

According to Olweus (1999), the criterion of repetition is highly relevant because it excludes infrequent, non-serious negative actions that are directed against different persons on different occasions. When the criterion of repetition is applied in the cyber context it becomes vaguer, and therefore, questions have been raised about the repetitiveness of bullying behaviour in the cyber context (Slonje and Smith 2008). In this regard several authors refer to the permanent and public nature of virtual communication: even if something is posted on the internet by the perpetrator only once it can be seen by multiple persons and it becomes extremely difficult to control or remove it because the information may have been downloaded, saved, and/or forwarded to a larger audience, and therefore, the situation may still fit into the criterion of repetition (Dooley et al. 2009, Kowalski et al. 2008, Shariff 2008, Slonje and Smith 2008). In addition, one-off posts can be viewed repeatedly by the victim and other onlookers (Kowalski et al. 2008). According to Dooley et al. (2009), there seem to be differences between the perpetrator and victim in terms of the perception of how many incidences occur and the potential consequences. Hence, in the cyber context, some acts do not need to be repeated (or repeated as often) to inflict harm and this makes repetition in cyberbullying different from faceto-face interaction (Dooley et al. 2009). Nocentini et al. (2010) reported from their focus group interviews that repetition was considered a very strong criterion in the context of cyberbullying because it helps to distinguish a joke from an intentional attack. Furthermore, participants from Italy and Germany referred to the relationship between repetition and publicity in online interaction because even if a single act of bullying was sent or shown only once to several people then it was still considered as a repetitive behaviour by the adolescents.

\subsubsection{Publicity vs. privacy}

Publicity in the cyber context is the opposite of a private form of communication involving only two parties. In short, the public nature of virtual communication includes communication where a large audience is involved (Nocentini et al. 2010). For example, if the photo or video is uploaded to some social networking site then an unlimited number of people can watch and share it and thus it becomes public. Nocentini et al. (2010) reported that the criterion of publicity is not essential for labelling an act as cyberbullying, but the criterion is still relevant because it may reflect the seriousness of the attack. In addition, adolescents from Italy, Germany, and Spain indicated that the presence of onlookers makes cyberbullying public. Similarly, the study by Slonje and Smith (2008) showed that bullying with picture/video clips was considered more severe than other forms of cyberbullying primarily because of large potential audience and because subjects can be identified. Making private information public was the most commonly used form of cyberbullying in the study by Lenhart (2007). Similarly, Patchin and Hinduja (2010) revealed that posting something online about another person to make others laugh was the most frequently reported form of cyberbullying. 


\subsubsection{Anonymity}

Some studies have shown that quite large numbers of cybervictims do not know who bullied them. For instance, in Kowalski and Limber's (2007) study the proportion was $48 \%$, in Li's (2007) study $46.6 \%$ and in Slonje and Smith's (2008) $32.8 \%$. This can be caused by the anonymous nature of cybercommunication that may encourage people to act in ways they would never consider in real life (Kowalski et al. 2008). Shielded screen names and false identities protect perpetrators and present them with an opportunity to act covertly and make it more difficult for the victim to tolerate (Kowalski et al. 2008, Shariff 2008). Previous studies have also discussed the role of anonymity in the context of cyberbullying behaviour (Mishna et al. 2009, Nocentini et al. 2010, Vandebosch and Cleemput 2008). For example, Vandebosch and Cleemput (2008) found in their focus group interviews conducted with Belgian students that the victim's feeling of powerlessness and frustration may be caused by the fact that the bully acts anonymously. In addition, the study showed that participants who had been bullied through electronic media had mostly received anonymous attacks. Mishna et al. (2008) conducted focus groups with 38 students between the fifth and eighth grades. They indicated that participants considered cyberbullying to be a serious problem because of the anonymity which let individuals behave in ways that they would never do in real life. But the results also revealed that the students' own experiences of cyberbullying were not so anonymous because they happened in the context of the students' social groups and relationships. Nocentini et al. (2010) found that in all study countries (Italy, Germany, and Spain) the criterion of anonymity was not considered a definitional criterion by the participants, but participants conveyed that it can cause insecurity and fear in the victims. Students also acknowledged that if the bully is a familiar person, someone you trust, or even someone with whom you have a friendly relationship, then the bullying attack would hurt more intensely.

To sum up, traditional bullying involves the first three aforementioned criteria: it is intentionally aggressive, based on an imbalance of power, and repeated (Olweus 1999). Even though cyberbullying may share these three characteristics, there are also two other criteria (public vs. private and perpetrator anonymity) that seem to be more specific in the cyber context.

\subsection{Types of cyberbullying behaviour}

Based on previous studies, Nocentini et al. (2010) summarized different categories of cyberbullying behaviour into four main typologies based on the nature of the attack: written-verbal behaviours, visual behaviours, impersonation, and exclusion. According to Nocentini et al. (2010), the written-verbal type of cyberbullying embraces written or verbal forms of behaviours or communication that take place through electronic media such as phone calls, text messages, email, instant messaging, blogs, social networking sites, etc. At the same time, visual behaviour includes posting, sending or sharing compromising pictures and 
videos in the cyber world (Nocentini et al. 2010). Impersonation refers to situations where the perpetrator discovers or steals the victim's password to gain access to his or her accounts in order to get that person in trouble or to damage that person's reputation or friendships (Kowalski et al. 2008, Willard 2007). Both in face-to-face and cyberspace interactions, people have the basic need to feel that they belong to a group (Kowalski et al. 2008, Williams et al. 2000). In the cyber world, exclusion is the situation where someone is intentionally and cruelly excluded from an online group or buddy list; for example, in the context of instant messaging or an online gaming environment (Willard 2007).

Previous studies have also tried to investigate the topic of different types of cyberbullying behaviour. For instance, in the study by Nocentini et al. (2010), Spanish adolescents named all behaviours (written-verbal, visual, exclusion, and impersonation) as bullying. According to Italian adolescents, the visual and the written-verbal behaviours were considered forms of cyberbullying, whereas there was more disagreement about impersonation and exclusion. In addition, German students thought that impersonation is more of a criminal act rather than cyberbullying. It was interesting that in German focus groups the term 'cyberbullying' emerged only in the context of exclusion scenarios. In the case of severity evaluation, results indicated that all adolescents in all countries considered the visual as the most serious behaviour. There were some cultural differences: Italian adolescents considered the visual and the written-verbal behaviours as the most severe, whereas in Spain and Germany the most severe behaviours were visual and impersonation.

\subsection{The present study}

The aim of this study is to examine how Estonian students' perception and definition of cyberbullying is affected by the five cyberbullying criteria (imbalance of power, intention, repetition, anonymity, and publicity/privacy) and by the type of cyberbullying behaviour (written-verbal, visual, exclusion, and impersonation). There were three main research questions in the study:

a) Which criteria are more important for defining cyberbullying?

b) Which criteria differentiate evaluations of the seriousness of cyberbullying behaviours?

c) Are there differences related to different types of cyberbullying behaviour?

\section{Method}

\subsection{Participants}

Two focus group interviews were conducted with 20 students from one secondary school located in South Estonia's largest city. The school was selected using convenience sampling. After gaining agreement from the school to participate in the study, the school social worker was instructed to select students 
randomly from the class list - every third boy and every third girl in the class list was chosen to participate in the focus group interview. Focus group 1 consisted of five boys and five girls, all them were in grade 6 and aged 12. The gender division was the same in focus group 2, but the students were from grade 9 and aged 15.

The participants for the questionnaire were drawn from 12 Estonian schools using the convenience sampling method. Data were collected from three schools in big towns, three in small towns, and six countryside schools. Six of the schools were secondary schools (from first to twelfth grades), the other six were basic schools (from first to ninth grades). The sample consisted of 336 adolescents from grade 5 to 9 . Student ages ranged from 11 to 17 years, with a mean age of 14.04 years $(S D=1.46)$. Of these, 118 studied in basic schools and 218 in secondary schools. In total, $52 \%$ of the students were male $(n=173)$ and $48 \%$ were female $(n=163)$.

\subsection{Measures}

Scenarios for focus group interviews were developed in the European project COST ACTION IS0801 working group WG1 (see Nocentini et al. 2010). In total, 10 scenarios were created mixing the presence and absence of five cyberbullying criteria (intention, imbalance of power, repetitiveness, anonymity, publicity/ privacy). Furthermore, the last four scenarios of 10 covered the four types of cyberbullying behaviour (written-verbal, visual, exclusion, and impersonation) (see Table 1). Focus groups were structured to answer two key questions:

(1) Which is the best term to label four scenarios describing different situations or behaviours that could be considered cyberbullying?

(2) In the context of the cyberbullying construct, how do adolescents differentiate and evaluate the severity of the scenarios according to the five cyberbullying criteria and four cyberbullying behaviour types?

A questionnaire on the definition of cyberbullying which had been developed in the European project COST ACTION IS0801 was used in this study. The validity of the questionnaire was confirmed by the panel of European experts from COST ACTION IS0801. The instrument was pre-tested to identify ambiguities and difficult questions. The term used to label cyberbullying more accurately was selected on the basis of the focus group results and then used as an input for the questionnaire. There were 32 scenarios where the presence and absence of 5 cyberbullying criteria were combined. These scenarios covered a range of four types of cyberbullying behaviours (see Table 1, also see Table A in the appendix for the presence or absence of the criteria for all scenarios). Students were asked to complete the questionnaire asking them to a) evaluate each scenario based on whether they think it is bullying or not, and b) if the answer was yes, then they were asked to evaluate the seriousness of the scenarios. Questionnaires included instructions for students explaining how to complete the forms. 
Table 1. Five cyberbullying criteria and four types of cyberbullying behaviour combined in the scenarios

\begin{tabular}{|c|c|c|c|}
\hline \multicolumn{2}{|c|}{5 cyberbullying criteria } & \multicolumn{2}{|c|}{4 types of cyberbullying behaviour } \\
\hline Intentionality & $\begin{array}{l}\text { "to intentionally hurt" vs. "as } \\
\text { a joke" }\end{array}$ & Written verbal & $\begin{array}{l}\text { "M. sent to C. a nasty } \\
\text { text message" }\end{array}$ \\
\hline Imbalance of power & $\begin{array}{l}\text { "C. was upset and didn`t know } \\
\text { how to defend himself/her- } \\
\text { self" vs. "C. didn`t care" }\end{array}$ & Visual & $\begin{array}{l}\text { "M. sent to C. a com- } \\
\text { promising photo" }\end{array}$ \\
\hline Repetition & $\begin{array}{l}\text { "several times during the last } \\
\text { month" vs. "once" }\end{array}$ & Exclusion & $\begin{array}{l}\text { "M. took C. off their } \\
\text { online group" }\end{array}$ \\
\hline Publicity/privacy & $\begin{array}{l}\text { "to other people to see" vs. } \\
\text { "only to C." }\end{array}$ & Impersonation & $\begin{array}{l}\text { "M. has got access to } \\
\text { C. `s password or } \\
\text { private information" }\end{array}$ \\
\hline Anonymity & $\begin{array}{l}\text { "C., who didn't know him/her } \\
\text { personally" vs. to C., a } \\
\text { familiar boy/girl }\end{array}$ & & \\
\hline
\end{tabular}

Note: $\mathrm{C}$ - victim; $\mathrm{M}$ - bully.

\subsection{Procedure}

Focus group interviews were conducted in autumn 2010. Ten scenarios were presented to the students during the focus group interviews. Each scenario was printed separately using a large font size on A4 paper to make it easier for students to read and understand the differences between the scenarios. Interviews were carried out in school during the school day by a moderator and a recorder. Both interviews were held using the same interview guide and the guidelines by Krueger (1994) and Morgan (1988) were followed. Focus group interviews lasted approximately 45 minutes. The focus groups were digitally recorded and transcribed verbatim.

The questionnaire study was undertaken between February and May 2011. Students filled in a questionnaire during school time in their classroom. Participation was voluntary. Teachers were instructed on how to carry out the questionnaire and provide help when needed. The questionnaire took 15-20 minutes to complete.

\subsection{Data analysis}

Thematic analysis was used in order to analyse the data gathered from the focus groups. The content of the transcribed text was coded in relation to the key questions in the interview guide (Morgan 1988) and the report from the focus group was organized in a question-by-question format using amplifying quotes and a descriptive summary. The coded statements were gathered under general themes and then the main themes and quotes were edited and summarized. The data analysis concentrated on the two main themes: (1) the term used to label cyberbullying; (2) severity across the five cyberbullying criteria and four types of cyberbullying behaviour and how they represent the construct. 
Percentages of "yes, it's cyberbullying" were recorded for the 32 scenarios presented by the four types of behaviour (written-verbal, visual, exclusion, and impersonation), and a chi-square analysis was performed on the data at the 0.01 significance level to analyse differences between the four types of behaviour.

Multidimensional scaling (MDS) was used to determine the underlying structure of the relationship between scenarios. MDS is an exploratory data analysis technique for analysing similarities or dissimilarities in data. It is essentially a form of data reduction which deals with 'dissimilarities' between objects in order to find their configuration in a geometrical space. It represents (dis)similarity data between objects by a variety of distance models (Jaworska and Chupetlovska-Anastasova 2009, Tsogo et al. 2000).

In order to perform MDS, the same procedure was followed as in the study by Smith et al. (2002). On the basis of that study, the percentage of participants who defined each scenario as 'bullying' were calculated to assess similarity or difference between any two scenarios by comparing the percentages profile and permitting an analysis of the structure of the scenarios over all respondents. In order to gain some insight into the differences between types of behaviour in the structure analysis, percentages of each of the four types of cyberbullying behaviour were calculated. Scenario 1 was the control scenario and therefore it was excluded from the data analysis procedure (see Appendix). Euclidean distance was used to create distance matrixes between scenarios for each type of cyberbullying behaviour. The MDS analysis was performed using the PROXSCAL algorithm in SPSS version 17.0. A generalized Euclidean Model was employed to weight the underlined dimensions on the basis of each type of behaviour (Borg and Groenen 2005).

Kruskal's (1964) recommendations were followed to determine the number of dimensions that provide the best fit with the data. Normalized Stress value was used in order to identify the number of dimensions; solutions were sought in one to four dimensions. According to Kruskal (1964), the Stress value ranges from 0 to 1; smaller Stress values indicate a better fit: $.20=$ poor; $.10=$ fair; $.05=$ good; $.025=$ excellent; $.00=$ perfect. In this study, the value of Stress was examined for solutions with dimensions from 1 to 4 .

To compare the seriousness of the scenarios among different quadrants Kruskal-Wallis and Mann-Whitney U tests were used.

\section{Results}

\subsection{Focus groups - the term, criteria, and typologies of behaviour}

To begin with, the most suitable term to describe cyberbullying behaviour was found based on focus group interviews. Participants understood that the content of the scenarios referred to the bullying acts via the internet and mobile phones. Adolescents differentiated the five cyberbullying criteria (imbalance of power, intention, repetition, anonymity, and publicity/privacy) and the types of cyberbullying behaviours (written-verbal, visual, exclusion, and impersonation) mainly 
based on the severity of the scenarios presented. Students used terms that referred to the cyber context 'internet bullying', 'bullying via cell-phone', and 'text-bullying'. However, the terms caused disagreements and disputes among the participants; these were not considered appropriate for labelling all the scenarios because they included bullying in both ways - via the internet and mobile phones. In addition, it seemed that adolescents were not able to classify mobile phones as part of the cyber world. The term 'bullying', which emerged from all scenarios presented in the focus group interviews, reflected a broad consensus. Therefore, the term 'bullying' was used as the input for the questionnaire.

Furthermore, the seriousness of the scenarios on the basis of cyberbullying criteria was investigated. It seemed that all the criteria were considered cyberbullying and all of them were serious for different reasons. The results showed that it was important to the students to know how the victim reacted to the bullying ("power imbalance": whether the victim did not care, or was upset and did not know how to defend himself/herself). Older students (15 years old) said that "if $C$. didn't care, then it was just a senseless incident". But if the power imbalance criteria were included then it was evaluated as very severe. Notably, the addition of other criteria, such as repetition, intentionality, publicity, and anonymity in the scenarios with the presence of the condition that "C. was upset and didn't know how to defend himself/herself" seemed to reinforce the imbalance in power relations from the students' point of view. Furthermore, it seemed that if the bullying action was public instead of private, then it was evaluated as very serious. Students explained that in the case of public cyberbullying there is a large audience involved, and therefore, the victim's reputation may become damaged. There was a scenario where the action was public, but the victim did not care. Students suggested that in such circumstances the victim should definitely care and feel disturbed. Younger students (12-years old) added that "the police can fine someone for this kind of bullying...actually it is deviant because this may truly hurt the person and damage his/her relationships." Furthermore, in the context of publicity, the older students made parallels with the Estonian movie Klass (The Class) followed by the TV series Klass: elu pärast (The Class: Life After), which dealt with the issue of school bullying that ended with a school shooting. After presenting the scenario that included publicity criteria, students said that it would be good material for the second full-length movie, the second part of The Class.

In the terms of repetition the older group said that "if $M$ sends something once and then leaves [the victim] alone then it is not significant but if it is repeated, then perhaps it is a serious case." In the context of intentionality, if the intention to hurt lay behind the bully's act, then the behaviour was considered bullying or even psychological violence and therefore very serious as well. Older students said that "here he/she sends these things intentionally, it is not a joke anymore, he/she literally wants to hurt others and this is a form of psychological violence".

There was more disagreement about the anonymity criteria. On the one hand, it was not considered very severe because if you do not know the person, then it does not seem to be a problem compared to the situation where the perpetrator is a 
familiar person. On the other hand, the presence of anonymity was considered severe because it is unknown who is behind these kinds of acts; he or she may be a dangerous person. Younger participants suggested going to the police in order to identify the person doing this.

Finally, in relation to typologies of cyberbullying, students suggested that 'visual' and 'impersonation' represent the cyberbullying construct better and they were considered more serious compared to the other two types (written-verbal and exclusion). In order to explain their positions, Estonian students said that the visual form of cyberbullying is more serious because it is most convincing; students said that "a picture can paint a thousand words". Younger students found that the visual cyberbullying act is the most humiliating. Older students added that "it depends on whether $M$ sends the image only to $C$, or sends it to a wider audience. If he sends to others, then yes... and you'll never know which kind of photos he still has..." In relation to impersonation, students stated that it is serious if a perpetrator finds out or steals someone's password to gain access to the accounts, then the bully can cause a lot of trouble for that person; for example, spreading private information or impersonating another person's name. In the context of written-verbal behaviour an older student said that "this is so simple and insignificant... if it happened through messages then it cannot be taken very seriously compared to the situation where he/she was told it in a face-to-face situation." But the students raised the topic of the content of the message and the person behind the act. Consequently, they admitted that the seriousness of such incidents also depends on the content of the message (whether it is just a vulgar joke or something more personal) and the person who sends these messages.

Exclusion was perceived to be the least serious by the students. It was considered a defensive reaction against aggressive behaviour to avoid or put an end to cyberbullying. In addition, blocking and ignoring the bullying action was the main reaction suggested by the students if they were asked what they would do in the specific situations. Moreover, several students raised the question of the causes, which led M. to the act of cyberbullying; before their assessments, they would have liked to have known the causes and intentions behind the perpetrator's act. Older students argued: "Maybe C. had bullied M. before and now M. wants to get back at him/her."

\subsection{Descriptive data on the questionnaire}

Figure 1 below shows the percentages of cyberbullying according to behaviour type in each scenario given in ascending order by average score (see Figure 1). Table 2 presents the chi-square of cyberbullying according to the type of behaviour in each scenario. The $\chi^{2}$ tests according to types of behaviour did not show significant differences in relation to scenarios 3, 4, 11, 14, and 16 (see Table 2). In all other cases, exclusion showed the lowest percentages of frequency as compared to the other types of behaviour. 


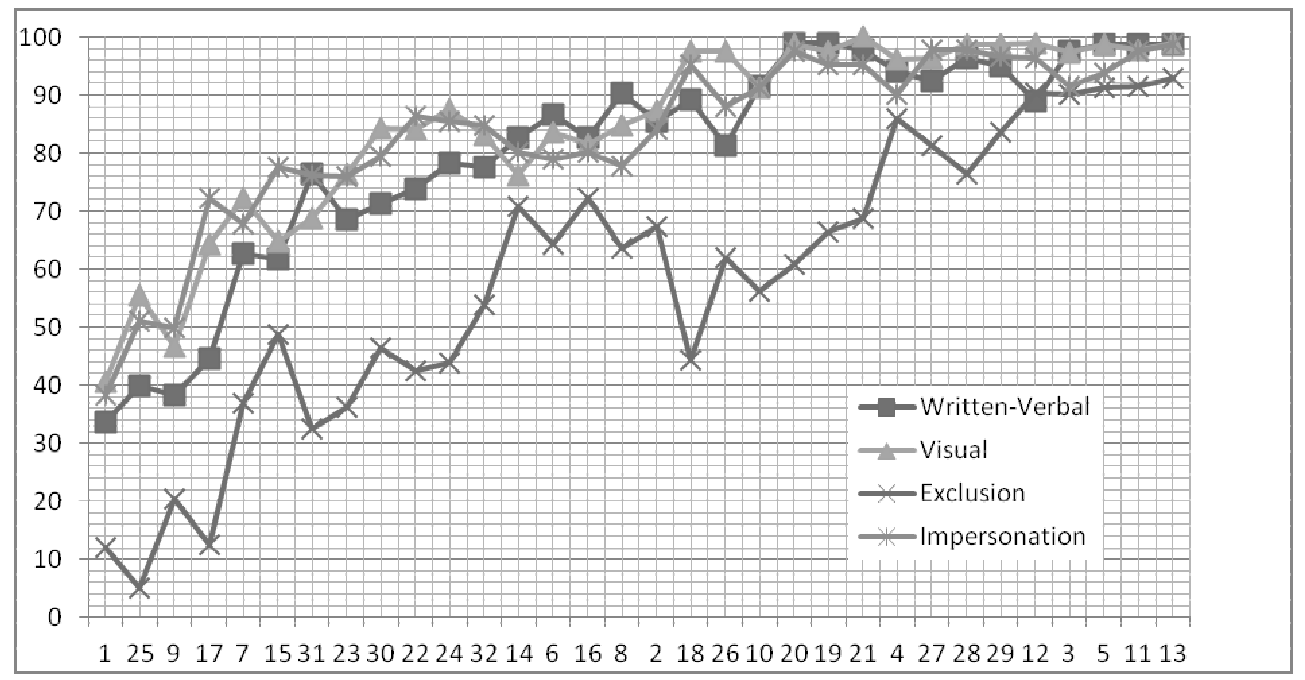

Figure 1. Percentages of "Yes, it is cyberbullying" according to type of behaviour in each scenario.

Table 2. Comparison of 4 types of behaviour (written-verbal, visual, exclusion, impersonation) in each scenario using the Chi-square

\begin{tabular}{|c|c|c|c|}
\hline Scenarios & Chi-Square & Scenarios & Chi-Square \\
\hline 1 & $21.393 * * *$ & 17 & $68.875^{* * *}$ \\
\hline 2 & $14.299 * *$ & 18 & $102.629 * * *$ \\
\hline 3 & 6.879 & 19 & $65.146^{* * *}$ \\
\hline 4 & 6.725 & 20 & $91.696 * * *$ \\
\hline 5 & $8.355^{*}$ & 21 & $61.954 * * *$ \\
\hline 6 & $14.838^{* *}$ & 22 & $48.249 * * *$ \\
\hline 7 & $27.260 * * *$ & 23 & $38.403 * * *$ \\
\hline 8 & $20.719 * * *$ & 24 & $52.280 * * *$ \\
\hline 9 & $18.369 * * *$ & 25 & $54.183 * * *$ \\
\hline 10 & $53.620 * * *$ & 26 & $38.304 * * *$ \\
\hline 11 & 7.73 & 27 & $19.507 * * *$ \\
\hline 12 & $9.932 *$ & 28 & $40.761 * * *$ \\
\hline 13 & $8.761 *$ & 29 & $19.157 * * *$ \\
\hline 14 & 3.781 & 30 & $33.902 * * *$ \\
\hline 15 & $14.540 * *$ & 31 & $46.216 * * *$ \\
\hline 16 & 3.342 & 32 & $27.312 * * *$ \\
\hline
\end{tabular}

\subsection{Multidimensional scaling}

The Stress values for one-, two-, three-, and four-dimensional solutions were $.06, .03, .01$ and .00 respectively. The two-dimensional MDS solution provided the 
best fit for these data as indicated by the stress values (badness of fit measures) and the inspection of the 'screen plot'. The improvement in fit beyond the twodimensional solution was negligible and the 'poorness-of-fit' did not decrease significantly. The level of variance in the input proximity matrices explained by the two-dimensional configuration is $96.43 \%$. Figure 2 provides a graphic representation of the two-dimensional aggregated solution.

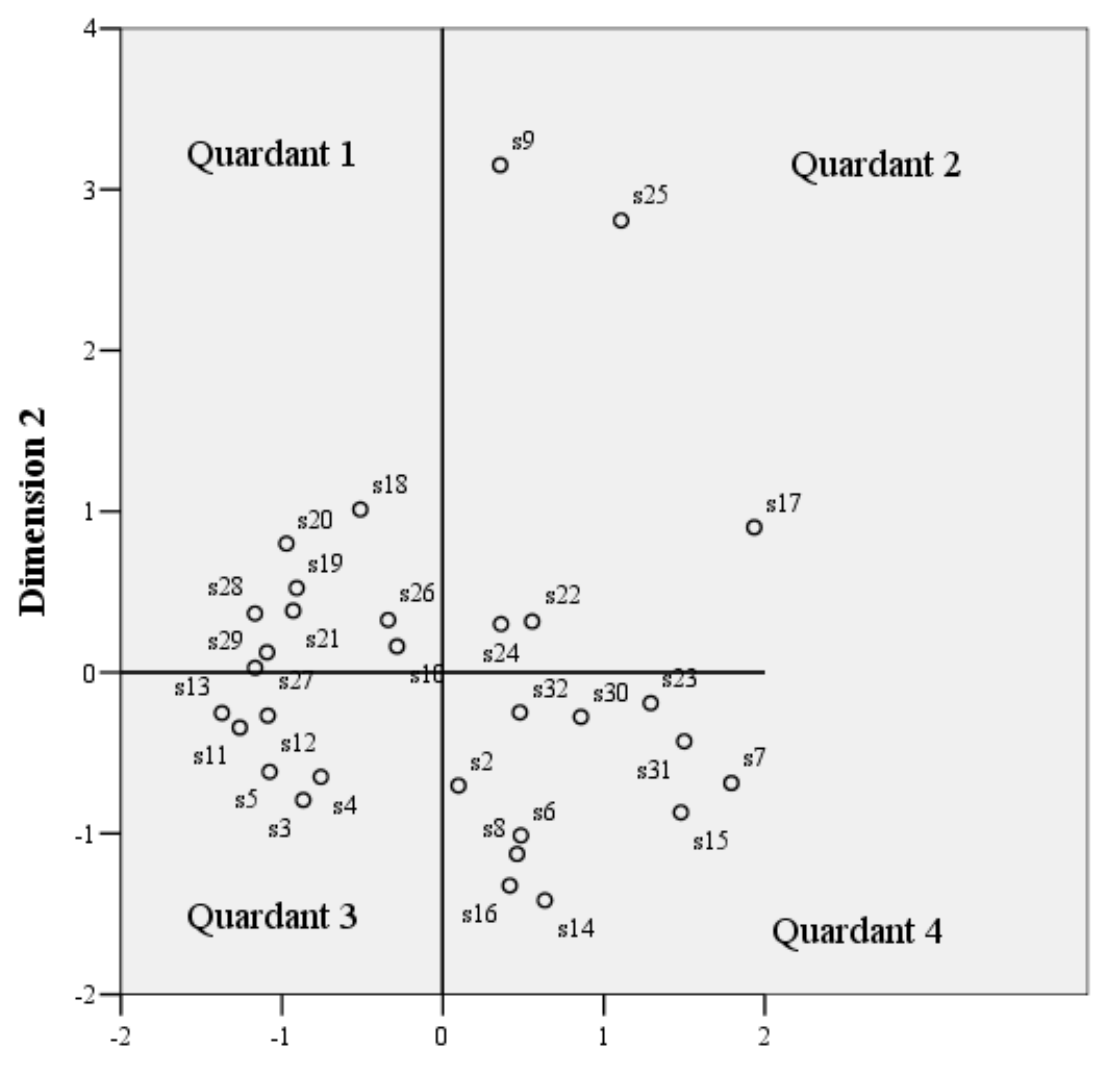

Dimension 1

Figure 2. Multidimensional Scaling solution of the structure of scenarios for 2 dimensions.

Firstly, to conceptualize the research results the scenarios above the 85th percentile and below the 15 th percentile on each dimension were compared. In dimension 1 (horizontal axis) in the MDS space (Figure 2), scenarios above the 85 th percentile are numbers $15,7,31$, and 17 and below the 15 th percentile are 11 , 13, 28, and 29. This dimension appeared to sort scenarios according to the presence or absence of the imbalance of power criterion. In particular, an examination of the first dimension revealed that scenarios on the left hand side of the 
figure (quadrants 1 and 3) are characterized by the presence of the imbalance of power, whereas scenarios on the right-hand side of the figure (quadrants 2 and 4) are characterized by the lack of this criterion.

In dimension 2 (vertical axis) in the MDS space (Figure 2), scenarios above the 85 th percentile are numbers $17,18,25$, and 9 and below the 15 th percentile are 14 , 16,8 , and 6 . Dimension 2 appeared to divide scenarios along an anonymity dimension. In that case, scenarios in the top of figure (quadrants 1 and 2) are characterized by the presence of anonymity, whereas scenarios in the bottom of figure (quadrants 3 and 4) are characterized by the lack of this criterion. There was one partial exception in this interpretation: scenario 9 does not present the criteria of anonymity, but is above the 85th percentile.

Secondly, to support our interpretation of the meaning of the dimensions we analysed the scenarios located over (quadrant 1 and 2) and under (quadrant 3 and 4) the horizontal axis, on the right side (quadrant 2 and 4) and on the left side (quadrant 1 and 3) of the vertical axis. This revealed that there were scenarios which were not located where we expected in relation to both the (horizontal and vertical) axes. In the horizontal axis scenario 2 , with the criteria power imbalance, is in quadrant 4 instead of quadrant 3 . In the vertical axis scenario numbers 23,30 , 31 , and 32 , all with the criteria of anonymity, are in quadrant 4 instead of quadrant 2 and, although scenario 9 does not include the criteria of anonymity, this is still in quadrant 2 instead of quadrant 4. Lastly, scenario 10 is in quadrant 1 instead of quadrant 3 because it does not include anonymity.

Thirdly, the consistency of this structure across the four types of behaviour was investigated. To further interpret the dimensions that underlie the space in Figure 2 , the interpretation of the consistency of this structure across the four types of behaviour was achieved by examining the 'dimension weights' calculated for the four proximity matrices (see Table 3 ). These weights range from 0 to 1 . The greater the magnitude of a given dimension weight, the greater the relevance of the associated attribute for conceptualizing those particular dimensions. The high dimension weight in the first dimension indicates the strong relevance of imbalance of power in the evaluation of scenarios for each type of behaviour considered. In contrast, the second dimension has a greater relevance in the definition of cyberbullying for written-verbal, visual, and impersonation scenarios as compared to exclusion. Therefore, we tried to do the MDS without exclusion but the results in that case were not so clear as with exclusion.

Table 3. Dimension weights for each type of behaviour on the two MDS dimensions

\begin{tabular}{l|c|c}
\hline \multicolumn{3}{c}{ Dimension } \\
\hline & 1 & 2 \\
\hline WRITTEN VERBAL & .615 & .287 \\
VISUAL & .568 & .378 \\
EXCLUSION & .684 & .059 \\
IMPERSONATION & .560 & .394 \\
\hline
\end{tabular}


Finally, in order to gain some insight into the topic of severity, the mean of seriousness for each scenario in each quadrant was calculated. Non-parametric tests (Kruskal-Wallis and Mann-Whitney) were applied to compare the means of the seriousness of scenarios between all four quadrants. Kruskal-Wallis tests showed that there were significant differences between the scenarios in different quadrants $(p<.01)$. The further analysis revealed that there were significant differences between quadrants 1 and 2 (Mann-Whitney $Z s=-2.803 ; p<.01$ ), 3 and 4 (Mann-Whitney Zs $=-3.317 ; \mathrm{p}<001), 1$ and 4 (Mann-Whitney $\mathrm{Zs}=-3.685$; $\mathrm{p}<.01$ ), and 2 and 3 (Mann-Whitney $Z s=-2.739 ; \mathrm{p}<.01$ ). No significant differences were found between quadrants 1 and 3 or 2 and 4 (Mann-Whitney test in both cases $\mathrm{p}>.05$ ). In short, the seriousness is important only in dimension 1 (imbalance of power) and not in dimension 2 (anonymity). Because the second dimension had a greater relevance to the definition of cyberbullying for writtenverbal, visual, and impersonation scenarios as compared to exclusion we tried to compare seriousness between the four quadrants without exclusion but the solution was negligible and the results were the same.

\section{Discussion}

The current study focused on the issues of cyberbullying criteria (imbalance of power, intention, repetition, anonymity, and publicity/privacy) and types of cyberbullying behaviour (written-verbal, visual, exclusion, and impersonation) in an attempt to gain more information about the perception and the definition of cyberbullying held by Estonian students.

The focus group interviews concentrated on finding the most suitable term to describe cyberbullying behaviours, which could be used in the quantitative part of the current study and also in future research to assess cyberbullying. In the study by Nocentini et al. (2010), the term 'bullying' emerged from focus group interviews and similarly in the Estonian case this was also the best term to label cyberbullying behaviour. The more specific term 'cyberbullying' did not emerge so clearly from the focus group interviews although there were terms that referred to the cyber context. If there were only internet specific or mobile phone specific scenarios, then we might assume that the terms used by the participants would have been different. There may also be a chance that, as in Italy, Germany, and Spain (Nocentini et al. 2010), the word 'cyber' is not widely used by adolescents even though it is present in the Estonian dictionary.

It was also the intention of this paper to analyse how cyberbullying criteria and types of behaviour can affect the definition and the perception of this problem by adolescents themselves following an approach previously used in other papers on a traditional bullying definition (Monks and Smith 2006, Smith et al. 2002). The first research questions covered the topic of cyberbullying criteria and their relevance for a cyberbullying definition. The results of the MDS indicated that, in order to evaluate a scenario as cyberbullying, Estonian adolescents mainly 
consider the presence of the imbalance of power criteria. Previous studies have also paid attention to the criteria of the imbalance of power (Dooley et al. 2009, Grigg 2010, Nocentini et al. 2010, Vandebosch and Cleemput 2008). The main discussions focused on how the imbalance of power in the cyber world differs from the imbalance of power in the 'real' world, and which characteristics make the bully stronger in the cyber context - what causes the imbalance in power relations in the virtual environment (Dooley et al. 2009, Grigg, 2010, Kowalski et al. 2008, Slonje and Smith 2008). However, scenarios developed for this study did not indicate how the imbalance was reached, or what caused the power imbalance or what was the antecedent of bullies' actions. The scenario referred directly to effects on the victim, who was upset and did not know how to defend himself/ herself and, as one explanation, this might have provoked empathic feelings in the participants. In addition, the relevance of the power imbalance criterion seems to be consistent with the outcomes of the focus group interviews, where it was evaluated as a very serious criterion by the adolescents. In addition, the differing weights of different types of behaviour were investigated. In the first dimension the relevance of imbalance of power was confirmed for all types of cyberbullying behaviour - written-verbal, impersonation, visual, and exclusion.

Anonymity, in the second dimension, was the second relevant criteria that emerged from the current study. In short, whether the act was performed anonymously or not was important to adolescents. Previous studies have also revealed the important role of anonymity in the context of cyberbullying behaviour and its criteria (Dooley et al. 2009, Hinduja and Pachin 2008, Kowalski and Limber 2007, Mishna et al. 2009). Similarly, the results of the study by Mishna et al. (2009) indicated that students perceived anonymity to be part of cyberbullying. Kowalski and Limber (2007) referred to their study outcome where almost half of the victims did not know who bullied them through electronic means. They concluded that the problem lies in the fact that the anonymity is an integral and dangerous part of the internet because first, the victim does not know whether there is one person or a group behind the bullying action and second, the anonymous enemy often frightens more than the enemy who is known (Kowalski and Limber 2007). At the same time, the importance and severity of the anonymity criterion did not emerge so clearly from the focus group interviews. One explanation may lie in the fact that the group interviews focused on the topic of severity and the underlying differences between the criteria, but in the questionnaire, students evaluated the relevance of different criteria for defining cyberbullying behaviour and thus anonymity was evaluated and considered relevant for cyberbullying.

In addition, the second dimension had more relevance for written-verbal, impersonation, and visual behaviours compared to exclusion. This result is supported by the fact that, adolescents evaluated exclusion as cyberbullying to a lesser extent in the questionnaires compared to other types of behaviours. This outcome is also in line with the outcomes of focus group interviews where exclusion and written-verbal behaviour were considered less serious compared to the other two types. 
The second research question focused on the issue of severity. According to the two-dimensional model revealed through MDS the result indicates that the seriousness was important only in dimension 1 (imbalance of power) and not in dimension 2 (anonymity). This means that adolescents perceived scenarios including the power imbalance criterion as more severe than the scenarios without it. In the context of anonymity the presence or absence of that criterion did not have an impact on the evaluation of severity. The topic of severity was also the subject matter of the focus group interviews. Unlike the questionnaire, the interviews concentrated on all five cyberbullying criteria, and therefore, these results revealed a better understanding of the topic. On the basis of the scenarios presented, adolescents considered all five criteria as part of cyberbullying behaviour, and consequently, the severity of each criterion was evaluated on the basis of the specific nature of the criterion. Even though all five criteria were considered serious in their own ways, it seemed that imbalance of power and publicity created more discussion, recognition, and emotions among the students. It seemed that, besides the direct consequences that referred to imbalance of power ("C. was upset and didn't know how to defend himself/herself"), the presence of other criteria had an impact on the severity evaluations in the sense that they further reinforced the imbalance of power criterion. The results are consistent with previous authors who have suggested that the anonymous and public nature of computer-mediated communication may create imbalances of power (Dooley et al. 2009, Kowalski et al. 2008, Slonje and Smith 2008). Still, the topic of the coexistence of the criteria in the context of severity needs further investigation in future studies.

In the context of publicity, one explanation is that students simply may have witnessed or experienced that kind of cyberbullying the most. This assumption is in line with previous studies which have shown that public bullying in the virtual environment is quite widespread (Lenhart 2007, Patchin and Hinduja 2010) and some forms of cyberbullying (e.g. picture/video clip) are estimated as more severe, especially because of the large potential audience involved (Slonje and Smith 2008). The topic of damaging reputation with public acts in the cyber world was raised by Estonian students as well. In accordance with the conclusion from Dooley et al. (2009:183): "the damage experienced in cyberbullying may be largely social and emotional in nature and is exacerbated by the potential scale of the damage inflicted". The severity of the anonymity criterion remains rather unclear on the basis of focus group interviews. One explanation may lie in the fact that in the focus groups the anonymity criterion was presented only in one scenario out of ten, while the other criteria were presented more frequently in the scenarios.

The third research question concentrated on the differences related to different types of cyberbullying behaviour. In the context of different cyberbullying behaviours, students indicated that impersonation and visual cyberbullying represent the cyberbullying construct better and these types were considered more serious compared to the two other types (written-verbal and exclusion). We may assume that for the Estonian adolescents exclusion is perceived as a coping 
strategy against cyberbullying because they are strongly recommended to exclude or block the 'bully' from their buddy list in order to avoid or put an end to cyberbullying. In addition, Estonian adolescents would have liked to have known the causes and intentions behind the perpetrator's act because in their opinion there may be the possibility that the bully actually acted to protect him/herself. The results of the Italian, German, and Spanish focus groups (Nocentini et al. 2010) showed that, similarly to Estonian adolescents, students from Spain and Germany estimated visual and impersonation as the most severe behaviours, whereas the Italian adolescents also considered visual as the most severe, but instead of impersonation, they considered written-verbal behaviour in second position. The severity of visual criterion may lie in the fact that there have been some extremely serious, even fatal, cyberbullying incidents in Estonia, which included a very significant visual component (pictures and videos), but also impersonation in the context of pretending to be someone else.

In conclusion, the results of this study showed that the scenarios and questionnaires developed by Nocentini et al. (2010) and by Menesini and collab. (in press) are able to determine the relevance of different criteria. This investigation provided a better understanding of cyberbullying from which future studies on basic knowledge and intervention strategies can proceed. In brief, adolescents defined cyberbullying behaviour first of all considering whether there was an imbalance of power between the bully and victim. Then, they evaluated whether the act was performed anonymously or not. Still, the research result in different countries has shown that adolescents from different countries may perceive and experience cyberbullying differently and that is why it is important to examine cyberbullying in a wide range of countries with different cultures and historical backgrounds (Li 2007).

The present study made a valuable contribution to the understanding of Estonian adolescents' definition of cyberbullying; however, potential limitations need to be considered as well. The relatively small sample size and the randomized administration of the scenarios may affect the generalization of the results to a wider population. Furthermore, personal involvement in cyberbullying (as bully and/or victim) and the perception and definition of cyberbullying could be an interesting topic to research to determine whether the definition is influenced by personal experience or not (Monks and Smith 2006). In line with the current research results, which indicated that the best term to label cyberbullying behaviour is 'bullying', it would be interesting to investigate whether and how adolescents themselves perceive the difference between bullying and cyberbullying. In other words, is cyberbullying a separate construct from traditional bullying or just a subcategory of traditional bullying that simply utilizes modern tools to conduct traditional bullying? Further studies are required in order to develop a more clear understanding of the nature of cyberbullying and its relationship with traditional bullying. 


\section{Acknowledgement}

The authors acknowledge the contribution of Working Group WG1 of the COST Action IS0801 project "Cyberbullying: Coping with negative and enhancing positive uses of new technologies, in relationships in educational settings." This study was also supported by the European Social Fund, project no 1.2.0401.09-0070

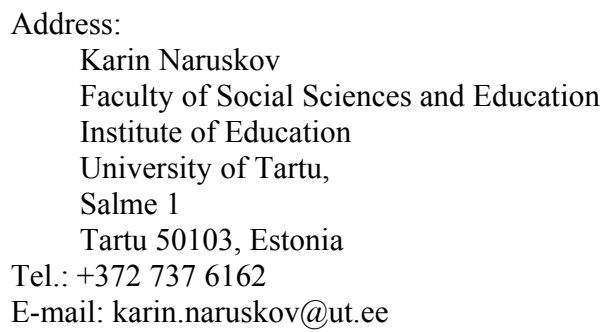

\section{References}

Borg, Ingwer and Patrick J. F. Groenen (2005) Modern multidimensional scaling. 2nd ed. New York: Springer.

Dooley, Julian J., Jacek Pyżalsky, and Donna Cross (2009) "Cyberbullying versus face to face bullying: a theoretical and conceptual review". Zeitschrift für Psychologie/Journal of Psychology 217, 4, 182-188.

Gradinger, Petra, Dagmar Strohmeier, and Christiane Spiel (2010) "Definition and measurement of cyberbullying". Journal of Psychosocial Research on Cyberspace 4, 2, 1-13.

Grigg, Dorothy Wunmi (2010) "Cyber-aggression: definition and concept of cyberbullying". Australian Journal of Guidance and Counselling 20, 2, 143-156.

Hinduja, Sameer and Justin W. Patchin (2008) "Cyberbullying: an exploratory analysis of factors related to offending and victimization". Deviant Behavior 29, 2, 129-156.

Hinduja, Sameer and Justin W. Patchin (2009) Bullying beyond the schoolyard: preventing and responding to cyberbullying. Thousand Oaks, CA: Sage Publications (Corwin Press).

Jaworska, Natalia and Angelina Chupetlovska-Anastasova (2009) "A review of multid.imensional scaling (MDS) and its utility in various psychological domains". Tutorials in Quantitative Methods for Psychology 5, 1, 1-10.

Kowalski, Robin M. and Susan P. Limber (2007) "Electronic bullying among middle school students". Journal of Adolescent Health 41, S22-S30.

Kowalski, Robin M., Susan P. Limber, and Patricia W. Agatston (2008) Cyber bullying: bullying in the digital age. Malden, MA: Blackwell Publishing.

Krueger, Richard A. (1994). Focus groups: a practical guide for applied research. 2 nd ed. Thousand Oaks: Sage.

Kruskal, Joseph B. (1964) "Multidimensional scaling by optimizing goodness of fit to nonmetric hypothesis". Psychometrics 29, 1-27.

Lenhart A. (2007) "Cyberbullying and online teens: Pew Internet \& American life project". http://www.pewinternet.org/ /media/Files/Reports/2007/PIP\%20Cyberbullying\%20Memo.pdf. pdf. Accessed 23.04.2012.

Li, Qing (2007) "Bullying in the new playground: research into cyberbullying and cyber victimization”. Australasian Journal of Educational Technology 23, 4, 435-454. 
Menesini, Ersilia and Annalaura Nocentini (2009) "Cyberbullying definition and measurement; some critical considerations". Zeitschrift für Psychologie/Journal of Psychology 217, 4, 230-232.

Menesini, Ersilia, Ada Fonzi, and Peter K. Smith (2002) "Attribution of meanings to terms related to bullying: a comparison between teacher's and pupil's perspectives in Italy". European Journal of Psychology of Education 17, 4, 393-406.

Menesini, Ersilia, Annalaura Nocentini, Benedetta E. Palladino, Ann Frisén, Sofia Berne, Rosario Ortega-Ruiz, Juan Calmaestra, Herbert Scheithauer, Anja Schultze-Krumbholz, Piret Luik, Karin Naruskov, Catherine Blaya, Julien Berthaud and Peter K. Smith (2012) "Cyberbullying definition among adolescents: A comparison across six European countries". Cyberpsychology, Behavior, and Social Networking 15, 9, 455-463.

Mishna, Faye, Michael Saini and Steven Solomon (2009) "Ongoing and online: children and youth's perception of cyberbullying." Children and Youth Services Review 31, 12, 1222-1228.

Monks, Claire P. and Peter K. Smith (2006) "Definitions of bullying: age differences in understanding of the term, and the role of experience". British Journal of Developmental Psychology 24, 4, 801-821.

Morgan, David L. (1988) Focus groups as qualitative research. Newbury Park, CA: Sage.

Nocentini, Annalaura, Juan J. Calmaestra, Anja Schultze-Krumblholz, Herbert Scheithauer, Rosario Ortega, and Ersilia Menesini (2010) "Cyberbullying: labels, behaviours and definition in three European countries". Australian Journal of Guidance and Counselling 20, 2, 129-142.

Olweus, Dan (1999) "Sweden”. In The nature of school bullying: a cross-national perspective, 7-27. Peter K. Smith, Yohji Morit, Josine Junger-Tas, Dan Olweus, Richard Catalano, and Philip Slee, eds. London: Routledge.

Patchin, Justin W. and Sameer Hinduja (2010) "Cyberbullying and self-esteem”. Journal of School Health 80, 12, 614-621.

Shariff, Shaheen (2008) Cyber-bullying: issues and solutions for the school, the classroom and the home. Abington, Oxfordshire, UK: Routledge (Taylor \& Frances Group).

Slonje, Robert and Peter K. Smith (2008) "Cyberbullying: another main type of bullying?" Scandinavian Journal of Psychology 49, 2, 147-154.

Smith, Peter K., Helen Cowie, Ragnar F. Olafsson, and Andy P.D. Liefooghe (2002) "Definitions of bullying: a comparison of terms used, and age and gender differences, in a fourteen-country international comparison". Child Development 73, 4, 1119-1133.

Smith, Peter K., Jess Mahdavi, Manuel Carvalho, Sonja Fisher, Shanette Russell, and Neil Tippett (2008) "Cyberbullying: its nature and impact in secondary school pupils". The Journal of Child Psychology and Psychiatry 49, 4, 376-385.

Smorti, Andrea, Ersilia Menesini and Peter K. Smith (2003) "Parents' definition of children's bullying in a five-country comparison". Journal of Cross-Cultural Psychology 34, 4, 417432.

Tsogo, L., M. J. Masson and Anna Bardot (2000) "Multidimensional scaling methods for manyobject sets: a review". Multivariate Behavioral Research 35, 3, 307-319.

Vaillancourt, Tracy, Patricia McDougall, Shelley Hymel, Amanda Krygsman, Jessie Miller, Kelley Stiver and Clinton Davis (2008) "Bullying: are researchers and children/youth talking about the same thing?" International Journal of Behavioural Development 32, 6, 486-495.

Vandebosch, Heidi and Katrien Van Cleemput (2008) "Defining cyberbullying: a qualitative research into the perceptions of youngsters". CyberPsychology \& Behavior 11, 4, 44994503 .

Willard, Nancy E. (2007) Cyberbullying and Cyberthreats: responding to the challenge of online social aggression, threats, and distress. Champaign, Illinois: Research Press.

Williams, Kipling D., Christopher K. T. Cheung, and Wilma Choi (2000) "Cyberostracism: effects of being ignored over the internet". Journal of Personality and Social Psychology 79, 5, 748762. 
APPENDIX

Table A. Presence $(\mathrm{Y})$ and absence $(\mathrm{N})$ of the criteria for all 32 scenarios

\begin{tabular}{|c|c|c|c|c|c|}
\hline Scenario & Intention & Repetition & $\begin{array}{c}\text { Imbalance of } \\
\text { Power }\end{array}$ & Public/private & Anonymity \\
\hline 1 & $\mathrm{~N}$ & $\mathrm{~N}$ & $\mathrm{~N}$ & PRI & $\mathrm{N}$ \\
\hline 2 & $\mathrm{~N}$ & $\mathrm{~N}$ & $\mathrm{Y}$ & PRI & $\mathrm{N}$ \\
\hline 3 & $\mathrm{Y}$ & $\mathrm{N}$ & Y & PRI & $\mathrm{N}$ \\
\hline 4 & $\mathrm{~N}$ & $\mathrm{Y}$ & $\mathrm{Y}$ & PRI & $\mathrm{N}$ \\
\hline 5 & $\mathrm{Y}$ & $\mathrm{Y}$ & $\mathrm{Y}$ & PRI & $\mathrm{N}$ \\
\hline 6 & $\mathrm{Y}$ & $\mathrm{N}$ & $\mathrm{N}$ & PRI & $\mathrm{N}$ \\
\hline 7 & $\mathrm{~N}$ & $\mathrm{Y}$ & $\mathrm{N}$ & PRI & $\mathrm{N}$ \\
\hline 8 & $\mathrm{Y}$ & $\mathrm{Y}$ & $\mathrm{N}$ & PRI & $\mathrm{N}$ \\
\hline 9 & $\mathrm{~N}$ & $\mathrm{~N}$ & $\mathrm{~N}$ & PUB & $\mathrm{N}$ \\
\hline 10 & $\mathrm{~N}$ & $\mathrm{~N}$ & $\mathrm{Y}$ & PUB & $\mathrm{N}$ \\
\hline 11 & $\mathrm{Y}$ & $\mathrm{N}$ & $\mathrm{Y}$ & PUB & $\mathrm{N}$ \\
\hline 12 & $\mathrm{~N}$ & $\mathrm{Y}$ & $\mathrm{Y}$ & PUB & $\mathrm{N}$ \\
\hline 13 & Y & $\mathrm{Y}$ & $\mathrm{Y}$ & PUB & $\mathrm{N}$ \\
\hline 14 & Y & $\mathrm{N}$ & $\mathrm{N}$ & PUB & $\mathrm{N}$ \\
\hline 15 & $\mathrm{~N}$ & Y & $\mathrm{N}$ & PUB & $\mathrm{N}$ \\
\hline 16 & Y & $\mathrm{Y}$ & $\mathrm{N}$ & PUB & $\mathrm{N}$ \\
\hline 17 & $\mathrm{~N}$ & $\mathrm{~N}$ & $\mathrm{~N}$ & PUB & $\mathrm{Y}$ \\
\hline 18 & $\mathrm{~N}$ & $\mathrm{~N}$ & $\mathrm{Y}$ & PUB & $\mathrm{Y}$ \\
\hline 19 & Y & $\mathrm{N}$ & Y & PUB & $Y$ \\
\hline 20 & $\mathrm{~N}$ & $\mathrm{Y}$ & $\mathrm{Y}$ & PUB & $\mathrm{Y}$ \\
\hline 21 & $\mathrm{Y}$ & $\mathrm{Y}$ & $\mathrm{Y}$ & PUB & $\mathrm{Y}$ \\
\hline 22 & $\mathrm{Y}$ & $\mathrm{N}$ & $\mathrm{N}$ & PUB & $\mathrm{Y}$ \\
\hline 23 & $\mathrm{~N}$ & $\mathrm{Y}$ & $\mathrm{N}$ & PUB & $\mathrm{Y}$ \\
\hline 24 & $\mathrm{Y}$ & $\mathrm{Y}$ & $\mathrm{N}$ & PUB & $\mathrm{Y}$ \\
\hline 25 & $\mathrm{~N}$ & $\mathrm{~N}$ & $\mathrm{~N}$ & PRI & $\mathrm{Y}$ \\
\hline 26 & $\mathrm{~N}$ & $\mathrm{~N}$ & $\mathrm{Y}$ & PRI & $\mathrm{Y}$ \\
\hline 27 & $\mathrm{Y}$ & $\mathrm{N}$ & $\mathrm{Y}$ & PRI & $\mathrm{Y}$ \\
\hline 28 & $\mathrm{~N}$ & $\mathrm{Y}$ & $\mathrm{Y}$ & PRI & $\mathrm{Y}$ \\
\hline 29 & $\mathrm{Y}$ & $\mathrm{Y}$ & $\mathrm{Y}$ & PRI & $\mathrm{Y}$ \\
\hline 30 & $\mathrm{Y}$ & $\mathrm{N}$ & $\mathrm{N}$ & PRI & $\mathrm{Y}$ \\
\hline 31 & $\mathrm{~N}$ & $\mathrm{Y}$ & $\mathrm{N}$ & PRI & $\mathrm{Y}$ \\
\hline 32 & $\mathrm{Y}$ & $\mathrm{Y}$ & $\mathrm{N}$ & PRI & $\mathrm{Y}$ \\
\hline
\end{tabular}


Copyright of TRAMES: A Journal of the Humanities \& Social Sciences is the property of Teaduste Akadeemia Kirjastus and its content may not be copied or emailed to multiple sites or posted to a listserv without the copyright holder's express written permission. However, users may print, download, or email articles for individual use. 